\title{
DAMPAK KONVERSI LAHAN PERTANIAN TERHADAP POLA PRODUKSI DAN POLA KONSUMSI RUMAHTANGGA PETANI DI KOTA MATARAM
}

\section{The Impact of Agricultural Land Conversion toward Production and Consumption Pattern of Farmer'sHousehold in Mataram City}

Andini Fitria Utami, Candra Ayu, Anwar

Program Studi Agribisnis Fakultas Pertanian UNRAM

\begin{abstract}
ABSTRAK
Penelitian ini dilakukan di Kota Mataram periode 2014-2017 dengan tujuan untuk mengetahui dampak konversi lahan terhadap pola produksi rumahtangga petani, untuk mengetahui dampak konversi lahan terhadap pola konsumsi rumahtangga petani dan untuk mengetahui masalah yang dialami petani akibat konversi lahan. Kecamatan Sekarbela dan Kecamatan Sandubaya adalah lokasi penelitian, dengan jumlah petani responden sebanyak 30 orang. Hasil penelitian menunjukkan bahwa, konversi lahan berdampak menambah ragam kegiatan ekonomi produktif keluarga namun mengakibat-kan penurunan kontribusi pendapatan usahatani Rp 4.427.128/tahun atau menurun $18,51 \%$ dari total pendapatan rumahtangga petani. Konversi lahan juga berdampak terhadap pola konsumsi pangan dan terhadap pola pola konsumsi non pangan keluarga petani. Masalah yang dihadapi petani setelah konversi lahan adalah harga pangan pokok yang tinggi, nilai tukar petani rendah, serangan hama/penyakit dan kesuburan tanah yang kurang baik.
\end{abstract}

Kata Kunci : konversi lahan, pola produksi, pola konsumsi

\begin{abstract}
This research was conducted in Mataram City for the period of 2014-2017 with the aim to know the impact of land conversion on farmer's household production pattern, to know the impact of land conversion to farmer household consumption pattern and to know problem experienced by farmer due to land conversion. Sekarbela Sub-District and Sandubaya Sub-District are the location of research. Respondents studied were 30 farmers. The result of the research shows that, the impact of land conversion is the addition of various productive economic activities in the farmer's household and decreased contribution of farming income Rp 4,427,128/year or decreased 18,51\% from total household income of farmer. Impact of land conversion to food consumption pattern that is change of consumption pattern Food and impacts on non-food consumption patterns. Problems experienced by farmers after land conversion are high staple food prices, low farmer exchange rates, poor pest/disease and soil fertility.
\end{abstract}

Keywords: land conversion, production pattern, consumption pattern 


\section{PENDAHULUAN}

Saat ini terjadi peningkatan jumlah penduduk di Indonesia sebesar 1,1\%. Salah satu wilayah di Indonesia yang mengalami peningkatan jumlah penduduk yakni Kota Mataram sebesar 2,83\% tiap tahunnya (BPP Kota Mataram, 2016). Seiring dengan peningkatan jumlah penduduk tersebut, keberadaan lahan terutama lahan pertanian menjadi semakin terancam dikarenakan meningkatnya aktivitas pembangunan ekonomi. Hal tersebut mengakibatkan permintaan akan lahan pertanian terus bertambah. Fenomena ini memacu terjadinya konversi lahan pertanian menjadi non pertanian, sehingga terjadi penyempitan lahan pertanian di Kota Mataram. Penyempitan lahan pertanian di Kota Mataram mengakibatkan terjadinya penurunan produksi petani, sehingga mengakibatkan berkurangnya perolehan pendapatan petani dari usahataninya sendiri. Melihat kejadian tersebut maka akan mempengaruhi kemampuan petani dalam pemenuhan standar hidup layak anggota keluarganya. Penurunan pendapatan petani dari usahataninya sendiri, mengharuskan petani mencari sumber pendapatan lain baik masih dalam bidang pertanian ataupun di luar pertanian agar tetap mampu memenuhi standar hidup layak. Hal ini yang dinamakan terjadinya perubahan pola produksi. Hal ini juga akan berpengaruh pada pola konsumsi rumahtangga petani baik dari jenis pangan maupun non pangan. Dari beberapa hal tersebut akibat konversi lahan juga akan menimbulkan masalah/hambatan yang dihadapi oleh petani.

Penelitian ini bertujuan untuk mengetahui dampak konversi lahan terhadap pola produksi rumahtangga petani di Kota Mataram, mengetahui dampak konversi lahan terhadap pola konsumsi pangan dan konsumsi non pangan rumahtangga petani di Kota Mataram dan mengetahui masalah/hambatan yang dihadapi petani akibat koversi lahan di Kota Mataram.

\section{METODE PENELITIAN}

Penelitian ini menggunakan metode deskriptif dengan unit analisisnya rumahtangga petani yang mengkonversi lahan pertanian. Penelitian ini dilaksanakan di Kecamatan Sekarbela dan Kecamatan Sandubaya secara purposive sampling. Penentuan responden dilakukakan secara accidental sampling dan purposive sampling dengan jumlah responden ditentukan secara quota sampling sebanyak 30 responden. Jenis data yang digunakan, yaitu data kuantitatif dan data kualitatif. Sumber data yang digunakan, yaitu data primer dan data sekunder. Analisis data menggunakan analisis pendapatan rumah tangga petani, jenis, jumlah dan nilai konsumsi pangan dan non pangan. Masalah petani diteliti dengan menginventarisasi dan mendeskripsikan hasil temuan di lapangan

\section{HASIL DAN PEMBAHASAN}

\section{Karakteristik Rumahtangga Responden}

Hasil penelitian menunjukan bahwa, pasca konversi lahan petani berstatus sebagai penyewa meningkat dimana pra konversi sebesar $77 \%$ menjadi $93 \%$ dari jumlah responden rumahtangga petani sedangkan status sebagai petani pemilik menurun dimana pra konversi sebesar $23 \%$ menjadi $7 \%$ sebagai petani pemilik dari jumlah responden rumahtangga rumahtangga petani. 
Berdasarkan gambaran status kepemilkikan lahan usahatani tampak bahwa kedudukan rumahtangga petani relatif lemah, sebab pasca konversi lahan jumlah petani pemilik penggarap relatif lebih sedikit. Bagi lahan pertanian dengan status sewa atau penyakap, sangat rentan lahannya untuk dialihfungsikan ke non pertanian apabila terbuka akses infrastruktur atau jalan (Tajidan, 2017).

Hasil penelitian menunjukkan bahwa, pasca konversi lahan rata-rata luas lahan garapan responden menurun dimana pra konversi sebesar 0,60 ha menjadi 0,39 ha. Hal ini disebabkan oleh terjadinya penyempitan lahan pertanian akibat konversi lahan di Kota Mataram, sehingga petani memiliki keterbatasan dalam menggarap lahan pertanian di Kota Mataram.

Hasil penelitian menunjukkan bahwa, beberapa responden yang pada awalnya tidak memiliki pekerjaan sampingan yang mana hanya mengandalkan pendapatan dari usahatani sendiri, saat pasca konversi lahan terjadi penambahan pekerjaan sampingan pada rumahtangga responden. Pasca konversi pekerjaan sampingan responden hanya sebagai buruhtani, nelayan, pedagang, peternak, buruh bangunan dan tukang ojek sedangkan pasca konversi bertambah menjadi pekasih, sopir truk dan tukang pijat. Hal ini disebabkan oleh penurunan pendapatan yang diterima petani dari usahatani sendiri akibat konversi lahan, sehingga mengharuskan petani mencari sumber pendapatan lain untuk memenuhi kebutuhan sehari-hari.

\section{Dampak Konversi Lahan Terhadap Pola Produksi Rumahtangga Petani}

Dampak konversi lahan terhadap pola produksi diteliti dengan membandingkan pola produksi pra konversi dan pasca konversi lahan. Produksi dalam penelitian ini adalah pendapatan rumahtangga responden, sedangkan pola produksi adalah keragaman kegiatan ekonomi produktif seluruh anggota keluarga responden. Selengkapnya dampak konversi lahan terhadap pola produksi rumahtangga petani disajikan pada Tabel 1.

Berdasarkan Tabel 1, kontribusi pendapatan pra konversi lahan sebesar Rp 18.598.487/LLG/tahun sedangkan pasca konversi lahan kontribusi pendapatan hanya sebesar Rp 14.171.359/LLG/tahun, sehingga terjadi penurunan kontribusi pendapatan usahatani sebesar Rp 4.427.128/LLG/tahun atau menurun 18,51\%. Hal tersebut diakibatkan karena berkurangnya luas lahan yang dikelola petani pasca terjadinya konversi dimana pra konversi rata-rata luas lahan garapan petani sebesar 0,60 ha menjadi 0,39 ha pasca konversi lahan, sehingga kemampuan produksi berkurang.

Pasca konversi lahan, terjadi penambahan kegiatan ekonomi produktif yakni sebagai pekasih. Saat pra konversi tidak ada petani yang bekerja sebagai pekasih namun pasca konversi terdapat dua orang yang bekerja sebagai pekasih dimana ratarata pendapatan yang diperoleh sebesar Rp 366.667/tahun atau meningkat 1,71\%. Hal ini dikarenakan akibat konversi lahan aliran air yang digunakan untuk irigasi persawahan terganggu, sehingga dibutuhkan seseorang untuk mengatur dan menjaga aliran air tersebut dimana dalam hal ini dibutuhkan seorang pekasih.

Kontribusi pendapatan petani yang bersumber dari kegiatan di bidang pertanian berkontribusi sangat tinggi terhahadap pendapatan rumah tangga, namun hal tersebut mengalami penurunan setelah konversi dimana penurunannya sebesar Rp 2.786.795/ tahun atau menurun $10,75 \%$. Hal tersebut terjadi akibat penurunan pendapatan yang cukup tinggi dari pendapatan usahatani tanaman pangan. 
Tabel 1. Dampak Konversi Lahan terhadap Pola Produksi Rumahtangga Petani di Kota Mataram Periode Tahun 2014-2017

\begin{tabular}{|c|c|c|c|c|c|c|}
\hline \multirow{2}{*}{ No. } & \multirow{2}{*}{\multicolumn{2}{|c|}{$\begin{array}{c}\text { Jenis Kegiatan } \\
\text { Ekonomi Produktif }\end{array}$}} & $\begin{array}{c}\text { *Pra } \\
\text { Konversi }\end{array}$ & $\begin{array}{l}\text { **Pasca } \\
\text { Konversi }\end{array}$ & \multicolumn{2}{|c|}{ Dampak } \\
\hline & & & $\begin{array}{c}\text { Nilal } \\
\text { (Rp/tahun) }\end{array}$ & $\begin{array}{c}\text { Nilal } \\
\text { (Rp/tahun) }\end{array}$ & $\begin{array}{c}\text { Nilal } \\
\text { (Rp/tahun) }\end{array}$ & $\begin{array}{l}\text { Persentase } \\
\quad(* \%)\end{array}$ \\
\hline \multirow[t]{7}{*}{1.} & Keg & atan Pertanian & & & & \\
\hline & a. & UT Tanaman Pangan & 18.598.487 & 14.171.359 & -4.427 .128 & $-18,51$ \\
\hline & b. & Buruh Tani & 930.000 & 1.386 .000 & 456.000 & 2,22 \\
\hline & c. & Beternak & 51.667 & 894.333 & 842.666 & 3,92 \\
\hline & d. & Nelayan & 120.000 & 95.000 & -25.000 & $-0,10$ \\
\hline & $E$ & Pekasih & - & 366.667 & 366.667 & 1,71 \\
\hline & & Jumlah (1) & 19.700 .154 & 16.913 .359 & -2.786 .795 & $-10,75$ \\
\hline \multirow[t]{7}{*}{2.} & Keg & atan Non Pertanian & & & 0 & 0,00 \\
\hline & a. & Pedagang & 1.352 .000 & 2.856 .000 & 1.504 .000 & 7,59 \\
\hline & b. & Ojek & 746.880 & 819.440 & 72.560 & 0,42 \\
\hline & c. & Buruh Bangunan & 236.000 & 544.000 & 308.000 & 1,64 \\
\hline & d. & Sopir Truk & - & 140.000 & 140.000 & 0,65 \\
\hline & & Tukang Pijat & - & 96.000 & 96.000 & 0,45 \\
\hline & & Jumlah (2) & 2.334 .880 & 4.455 .440 & 2.120 .560 & 10,75 \\
\hline \multicolumn{3}{|c|}{ Total Pendapatan RT Petani } & 22.035 .034 & 21.368 .799 & -666.235 & $-3,02$ \\
\hline \multicolumn{3}{|c|}{ Keterangan: ${ }^{*}$ Periode $2014-2017$} & **Pasca 20 & & & \\
\hline
\end{tabular}

Setelah terjadi konversi lahan, tidak hanya kegiatan berbasis pertanian saja yang mengalami penambahan, dari non pertanian juga menjadi semakin beragam. Selain itu, seluruh anggota rumahtanga akan berperan penuh dalam mencari nafkah. Hal ini dikarenakan pasca konversi lahan terjadi petani tidak bisa meningkatkan intensitas kegiatan usahataninya karena luas lahan garapannya yang berkurang, sehingga perlu adanya kegiatan ekonomi produktif yang lain dari luar pertanian. Salah satunya yakni ada penambahan kegiatan ekonomi berbasis non pertanian setelah terjadi konversi lahan yakni sebagai sopir truk dimana pendapatan yang diperoleh sebesar Rp 140.000/tahun atau meningkat $0,65 \%$ dari total pendapatan rumahtangga petani. Hal ini akibat terjadi konversi, pendapatan yang diperoleh petani menurun dari usahtaninya sendiri sehingga untuk memenuhi kebutuhan pangan dan non pangan petani mencari sumber pendapatan lain yakni salah satunya sebagai buruh bangunan. Hal ini juga didukung dari adanya peningkatan aktivitas pembangunan akibat konversi, sehingga banyak dibutuhkan sopir truk untuk mengangkut bahan bangunan.

Selain itu terjadi penambahan kegiatan ekonomi produktif sebagai tukang pijat dengan pendapatan $\mathrm{Rp}$ 96.000/tahun atau meningkat 0,45 \% dari total pendapatan rumahtangga petani. Oleh karena itu kontribusi pendapatan petani yang bersumber dari non pertanian mengalami peningkatan sebesar Rp 2.120.560/tahun atau meningkat $10,25 \%$ dari total pendapatan rumahtangga petani. Walaupun pendapatan yang bersumber dari bidang non pertanian mengalami peningkatan akibat konversi lahan dan terjadi perubahan pola produksi akibat konversi lahan, namun total pendapatan rumahtangga petani menurun sebesar Rp 666.235/tahun atau menurun $3,02 \% \%$ dari total pendaptan rumahtangga petani. 


\section{Dampak Konversi Lahan Terhadap Pola Konsumsi Rumahtangga Petani}

Konsumsi pangan terdiri dari beras, lauk pauk, sayuran dan buah-buahan. Konsumi non pangan terdiri dari bahan bakar, biaya pendidikan, biaya kesehatan, pakaian, barang-barang tahan lama, dan rekreasi. Penjelasan tentang dampak konversi lahan terhadap pola konsumsi dijelaskan pada pembahasan berikut.

\subsection{Dampak Konversi Lahan Terhadap Pola Konsumsi Pangan Rumahtangga Petani}

Sebagian besar petani responden makan tiga kali per hari baik itu pra maupun pasca konversi lahan. Namun demikian, terjadi perubahan dalam ragam bahan makanan yang dikonsumsi oleh petani. Berdasarkan Tabel 2, akibat konversi lahan konsumsi pangan anggota rumahtangga petani responden menurun sebesar 0,30 $\mathrm{kg} / \mathrm{kapita} / \mathrm{bulan}$ senilai dengan Rp 13.648,81/kapita/bulan atau menurun 1,54 \% dari total kosumsi pangan rumahtangga petani. Hal ini dikarenakan akibat konversi pendapatan rumahtangga petani berkurang sehingga menyebabkan penurunan daya beli petani.

Konsumsi bahan pangan terbesar baik saat pra maupun pasca konversi lahan yakni pada konsumsi beras dimana pra konversi sebesar 9,37 kg/kapita/bulan senilai dengan Rp 72.666,67/kapita/bulan atau 48,23 \% dan pasca konversi sebesar 9,37 $\mathrm{kg} / \mathrm{kapita} / \mathrm{bulan}$ senilai dengan Rp 79.014,62/kapita/tahun atau 48,99 \%. Berdasarkan persentase terhadap total jumlah konsumsi pangan konsumsi beras mengalami peningkatan sebesar $0,76 \%$. Hal ini dikarenakan semakin banyak kegiatan yang dilakukan petani pasca konversi lahan sehingga dibutuhkan energi yang banyak, dimana perolehan energi terbesar yakni dari jenis karbohidrat. Hal tersebut juga terjadi pada konsumsi umbi-umbian dimana terjadi peningkatan jumlah konsumsi sebesar 0,17 kg/kapita/bulan senilai dengan $\mathrm{Rp} 5.023,98 / \mathrm{kapita} /$ bulan atau sebesar 0,83\% dari total konsumsi rumahtangga petani. Peningkatan konsumsi pada jenis umbiumbian dipilih petani, selain untuk mengganti kalori yang hilang karena penurunan konsumsi pada bahan makanan jenis lain, juga karena jenis makanan umbi-umbian memiliki harga yang murah, mudah didapatkan dan mengenyangkan, sehingga konsumsi jenis karbohidrat pasca konversi mengalami peningkatan sebesar 1,60 \% .

Konsumsi bahan pangan yang memberikan penurunan konsumsi tertinggi akibat konversi lahan adalah konsumsi lauk hewani sebesar $0,19 \mathrm{~kg} / \mathrm{kapita} / \mathrm{bulan}$ senilai

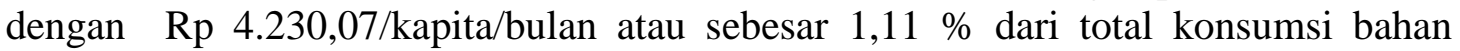
pangan. Penurunan tertinggi pada lauk hewani tersebut yakni pada jenis dagingdagingan yakni sebesar $0,08 \mathrm{~kg} / \mathrm{kapita} / \mathrm{bulan}$ senilai dengan $\mathrm{Rp} 3.160,13 / \mathrm{kapita} / \mathrm{bulan}$ atau sebesar $0,48 \%$ dari total konsumsi bahan pangan. Penurunan tersebut diakibatkan karena terjadi penurunan pendapatan sehingga menurunkan daya beli petani.

Namun penurunan konsumsi lauk hewani sebesar 1,11\% dari total konsumsi pangan menyebabkan peningkatan konsumsi lauk nabati sebesar $0,67 \mathrm{~kg} / \mathrm{kapita} / \mathrm{bulan}$

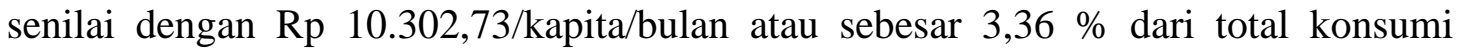
bahan pangan. Selain itu dapat dilihat juga terjadi peningkatan jumlah konsumsi sayuran sebesar $0,11 \mathrm{~kg} / \mathrm{kapita} / \mathrm{bulan}$ senilai dengan $\mathrm{Rp} 2.565,04 / \mathrm{kapita} / \mathrm{bulan}$ atau sebesar $0,42 \%$ dari total konsumsi bahan pangan. Petani lebih memilih memperbanyak konsumsi sayur dan lauk nabati karena lebih terjangkau harganya untuk menggantikan konsumsi lauk hewani. Oleh karena itu, terjadi perubahan pola 
konsumsi pangan dimana pra konversi yakni karbohidrat-sayuran-lauk hewani-lauk nabati-buah, sedangkan pasca konversi karbohidrat-sayuran-lauk nabati-lauk hewanibuah.

Tabel 2. Dampak Konversi Lahan terhadap Pola Konsumsi Pangan Rumahtangga Petani di Kota Mataram

\begin{tabular}{|c|c|c|c|c|c|c|c|c|}
\hline \multirow[b]{2}{*}{ Vo. } & \multirow[b]{2}{*}{$\begin{array}{l}\text { Jenis Konsumsi } \\
\text { Pangan }\end{array}$} & \multicolumn{2}{|c|}{ Pra Konversi } & \multicolumn{2}{|c|}{ Pasca Konversi } & \multicolumn{3}{|c|}{ Dampak } \\
\hline & & $\begin{array}{l}\text { Jumlah } \\
\text { (kapita/ } \\
\text { Bulan) }\end{array}$ & $\begin{array}{c}\text { Nilai } \\
\text { (Rp/kapita/ } \\
\text { Bulan) }\end{array}$ & $\begin{array}{l}\text { Jumlah } \\
\text { (kapita/ } \\
\text { Bulan) }\end{array}$ & $\begin{array}{c}\text { Nilai } \\
\text { (Rp/kapita/ } \\
\text { Bulan) }\end{array}$ & $\begin{array}{r}\text { Jumlah } \\
\text { (kapita/ } \\
\text { Bulan) }\end{array}$ & $\begin{array}{c}\text { Persentase } \\
\text { (\%) }\end{array}$ & $\begin{array}{c}\text { Nilai } \\
\text { (Rp/kapita/ } \\
\text { Bulan) }\end{array}$ \\
\hline 1. & Karbohidrat & & & & & & & \\
\hline a. & Beras (Kg) & 9,37 & $72.666,67$ & 9,37 & $79.014,62$ & 0,00 & 0,76 & $6.347,95$ \\
\hline b. & Umbi-umbian (Kg) & 0,72 & $5.350,00$ & 0,89 & $10.373,98$ & 0,17 & 0,83 & $5.023,96$ \\
\hline & Jumlah (1) & 10,09 & 78016,67 & 10,26 & $89.388,60$ & 0,17 & 1,60 & $11.371,93$ \\
\hline 2. & Lauk Hewani (Kg) & & & & & & & \\
\hline a. & Daging & 0,47 & $20.128,33$ & 0,39 & $16.968,21$ & $-0,08$ & $-0,48$ & $-3.160,13$ \\
\hline b. & Ikan Asin & 0,18 & $12.336,67$ & 0,18 & $15.760,44$ & 0,00 & 0,01 & $3.160,13$ \\
\hline c. & Ikan Segar & 0,57 & $16.466,67$ & 0,50 & $16.652,56$ & $-0,07$ & $-0,41$ & 185,89 \\
\hline d. & Telur & 0,40 & $4.800,00$ & 0,37 & $5.607,49$ & $-0,03$ & $-0,20$ & 807,49 \\
\hline & Jumlah (2) & 1,62 & $50.700,81$ & 1,45 & $46.470,74$ & $-0,19$ & $-1,11$ & $-4.230,07$ \\
\hline 3. & Lauk Nabati (Kg) & 1,36 & $8.660,00$ & 2,03 & $18.962,73$ & 0,67 & 3,36 & $10.302,73$ \\
\hline 4. & Sayuran (Kg) & 1,82 & $13.500,00$ & 1,93 & $16.065,04$ & 0,11 & 0,42 & $2.565,04$ \\
\hline 5. & Minyak Kelapa (Itr) & 1,00 & $9.150,00$ & 1,00 & $11.512,34$ & 0,00 & 0,08 & $2.362,34$ \\
\hline 6. & Gula (Kg) & 0,63 & $7.345,83$ & 0,63 & $8.873,21$ & 0,00 & 0,05 & $1.527,38$ \\
\hline 7. & Bahan Minuman $(\mathrm{Kg})$ & 0,16 & $6.351,11$ & 0,16 & $8.486,67$ & 0,00 & 0,00 & $1.065,35$ \\
\hline 8. & Buah-Buahan (Kg) & 0,67 & $7.366,67$ & 0,50 & $7.115,56$ & $-0,17$ & $-0,91$ & $-251,10$ \\
\hline 9. & Bumbu-Bumbuan & 1,77 & $37.490,33$ & 1,47 & $46.140,76$ & $-0,30$ & $-1,69$ & $8.650,43$ \\
\hline & Total & 19,42 & $217.025,82$ & 19,12 & $226.847,46$ & $-0,30$ & 1,54 & $-13.648,81$ \\
\hline
\end{tabular}

Berdasarkan data pada Tabel 2, terjadi peningkatan nilai konsumsi bahan pangan. Hal ini disebabkan oleh adanya rentang waktu penelitian yakni selama tiga tahun (2014-2017), sehingga terjadinya inflasi/perubahan harga pada setiap jenis bahan pangan dimana rata-rata suku bunga pada periode tersebut sebesar 6,25\%.

\subsection{Dampak Konversi Lahan Terhadap Pola Konsumsi non Pangan Rumahtangga Petani}

Pola konsumsi non pangan yang dimaksud dalam penelitian ini adalah intensitas pengeluaran biaya untuk kegiatan kegiatan sehari-hari. Berdasarkan Tabel 3 dapat dilihat bahwa jumlah pengeluaran konsumsi non pangan setelah terjadi koversi lahan mengalami penurunan sebesar Rp 17.462,48/kapita/bulan atau sebesar 10,03\%. Hal ini disebabkan karena penurunan pendapatan yang diperoleh petani, sehingga menurunkan daya beli.

Dampak penurunan tertinggi setelah terjadi konversi lahan adalah pengeluaran konsumsi non pangan untuk tabungan sebesar Rp 22.074,51 atau 12,04\% dari total 
konsumsi non pangan. Hal ini disebabkan karena berkurangnya pendapatan yang diperoleh petani sehingga kemampuan petani untuk menabung berkurang.

Konsumsi non pangan lainnya yang mengalami penurunan nilai konsumsi yakni pembelian pakaian, biaya kesehatan, dan biaya rekreasi, dimana masing-masing sebesar Rp 4.852,17/kapita/bulan atau sebesar 2,68 \% dari total konumsi non pangan, Rp 3.275,21/kapita/bulan atau sebesar 1,81 \% dari total konumsi non pangan, Rp $6.599,14 /$ kapita/bulan atau sebesar 3,68 \% dari total konsumsi non pangan. Sedangkan untuk nilai konsumsi penggunaan pulsa handphone mengalami penurunan sebesar Rp 817,04/kapita/bulan namun bila dilihat persenatsae dari kontribusi konsumsi untuk pulsa pasca naik sebesar 1,44 \% hal ini dikarenakan kebutuhan akan pulsa semakin meningkat dimana saat ini pulsa digunakan untuk mencari informasi/berita terbaru dengan mengkases internet dan proses komunikasi, sehingga kebutuhannya akan meningkat setiap waktu. Hal tersebut sama halnya dengan pemakaian listrik dimana terjadi penurunan sebesar Rp 5.700,46/kapita/bulan, namun kontribusi konsumsinya mengalami peningkatan sebesar 2,68 \% dari total konumsi non pangan hal ini karena nilai tukar listrik semakin meningkat. Untuk penurunan nilai konsumsi non pangan pada biaya pendidikan sebesar Rp 282,20/kapita/bulan, disebabkan oleh berkurangnya anggota keluarga yang bersekolah karena sudah lulus dari sekolah menengah atas. Rinciannya dapat dilihat pada Tabel 3.

Tabel 3. Dampak Konversi Lahan terhadap Pola Konsumsi non Pangan Rumahtangga Petani di Kota Mataram

\begin{tabular}{|c|c|c|c|c|c|c|c|}
\hline \multirow{2}{*}{\multicolumn{2}{|c|}{$\begin{array}{l}\text { Jenis Konsumsi } \\
\text { Non Pangan }\end{array}$}} & \multicolumn{2}{|c|}{ Pra Konversi } & \multicolumn{2}{|c|}{ Pasca Konversi } & \multicolumn{2}{|c|}{ Dampak } \\
\hline & & $\begin{array}{c}\text { per Kapita } \\
\text { (Rp/kapital } \\
\text { Minggu) }\end{array}$ & $\begin{array}{l}\text { per Kapita } \\
\text { (Rp/kapital } \\
\text { Bulan) }\end{array}$ & $\begin{array}{c}\text { per Kapita } \\
\text { (Rp/kapital } \\
\text { Minggu) }\end{array}$ & $\begin{array}{c}\text { per Kapita } \\
\text { (Rp/kapital } \\
\text { Bulan) }\end{array}$ & $\begin{array}{l}\text { (Rp/kapita/ } \\
\text { Bulan) }\end{array}$ & $\begin{array}{l}\text { Persentase } \\
\quad(\%)\end{array}$ \\
\hline \multicolumn{2}{|c|}{$\begin{array}{l}\text { Gas/Minyak Tanah }(\mathrm{Kg}) \\
\text { Kebersihan }\end{array}$} & $5.528,46$ & $22.113,82$ & $5.801,65$ & $23.206,61$ & $1.092,79$ & 2,11 \\
\hline$a$ & Sabun Cuci (Kg) & 841,46 & $3.365,85$ & 948,84 & $3.795,37$ & 429,52 & 0,49 \\
\hline $\mathrm{b}$ & Sabun Mandi (Kg) & $1.684,55$ & $6.738,21$ & $1.834,71$ & $7.338,84$ & 600,63 & 0,81 \\
\hline \multicolumn{2}{|c|}{ Jumlah (1) } & $2.526,02$ & $10.104,07$ & $2.783,55$ & $11.134,21$ & $1.030,15$ & 1,30 \\
\hline \multicolumn{2}{|c|}{ Pakaian } & $1.626,02$ & $6.504,07$ & 413,22 & $1.652,89$ & $-4.851,17$ & $-2,68$ \\
\hline \multicolumn{2}{|c|}{ Kesehatan } & $1.087,40$ & $4.349,59$ & 268,60 & $4.074,38$ & $-3.275,21$ & $-1,81$ \\
\hline \multicolumn{2}{|c|}{ Pendidikan } & 731,71 & $2.926,83$ & 661,16 & $6.666,67$ & $-282,20$ & 0,01 \\
\hline \multicolumn{2}{|c|}{ Rekreasi } & $2.063,01$ & $8.252,03$ & 413,22 & $6.666,67$ & $-6.599,14$ & $-3,68$ \\
\hline \multicolumn{8}{|c|}{ Biya Lain-lain } \\
\hline a & Tabungan & $7.997,97$ & $31.991,87$ & $2.479,34$ & $43.333,33$ & $-22.074,51$ & $-12,04$ \\
\hline$b$ & Pulsa & $7.642,28$ & $30.569,11$ & $7.438,02$ & $29.752,07$ & $-817,04$ & 1,44 \\
\hline c & Listrik & $18.780,49$ & $75.121,95$ & $17.355,37$ & $69.421,49$ & $-5.700,46$ & 1,17 \\
\hline$d$ & Bensin & $3.539,63$ & $14.158,54$ & $4.024,59$ & $16.098,35$ & $1.939,81$ & 2,15 \\
\hline \multicolumn{2}{|c|}{ Jumlah (2) } & $29.962,40$ & $119.849,59$ & $28.817,98$ & $115.271,90$ & $-4.577,69$ & 4,75 \\
\hline \multicolumn{2}{|c|}{ tal Konsumsi non Pangan } & $43.525,00$ & $174.100,00$ & $36.859,38$ & $165.637,52$ & $-17.462,48$ & \\
\hline
\end{tabular}


Selain itu dapat dilihat terjadi peningkatan nilai konsumsi pada pengeluaran gas/minyak tanah sebesar Rp 1.092,79/kapita/bulan, pengeluaran sabun cuci sebesar Rp 429,52/kapita/bulan dan pengeluaran sabun mandi sebesar Rp 600,63/kapita/bulan. Hal ini dikarenakan adanya rentang waktu penelitian yakni selama tiga tahun sehingga terjadi peningkatan harga pada masing-masing jenis konsumsi non pangan dimana kuantitas pemakaian tetap setelah konversi.

Nilai pengeluaran untuk bensin pada kendaraan juga mengalami peningkatan sebesar Rp 1.939,81/bulan/kapita. Hal ini disebabkan karena ada penambahan kepemilikan kendaraan pada petani responden dimana modal pembelian motor diperoleh dari hasil penjualan lahan, sehingga kebutuhan akan bahan bakar bensin meningkat.

Dapat disimpulkan bahwa dampak konversi lahan terhadap pola konsumsi non pangan adalah terjadinya penurunan pengeluaran konsumsi non pangan akibat penurunan pendapatan yang diperoleh oleh petani. Petani mengurangi pengeluaran biaya-biaya yang dirasa bisa dikurangi yang bukan merupakan kebutuhan pokok, seperti pakaian, rekreasi, pulsa, listrik dan tabungan.

\section{Masalah dan Hambatan yang dihadapi Petani}

Masalah dalam penelitian ini adalah sesuatu yang menghambat kegiatan usahatani dan ketercukupan dalam mengkonsumsi bahan makanan akibat terjadinya konversi lahan di Kota Mataram. Masalah terbanyak yamg dirasakan petani adalah harga bahan makanan yang semakin tinggi. dimana masalah tersebut paling banyak dirasakan oleh petani. Hal ini karena pendapatan petani dari usahatani sendiri/tanaman pangan yang berkurang akibat konversi lahan lalu diikuti dengan peningkatan pada hampir semua bahan makanan. Dengan kenaikan harga bahan makanan tersebut anggota keluarga petani harus menurunkan konsumsi bahan makanan mereka terutama pada lauk hewani. Selanjutnya yakni nilai tukar petani rendah tidak seperti pra konversi lahan. Hal ini dirasakan dari ketidakmampuan responden dalam membeli bahan pangan yakni beras. Kemudian yakni masalah hama/penyakit dan kesuburan tanah. Penyakit yang sering menyerang padi milik petani adalah busuk batang dan tungro.

\section{KESIMPULAN DAN SARAN}

\section{Kesimpulan}

a. Dampak konversi lahan terhadap pola produksi rumahtangga petani di Kota Mataram adalah penambahan ragam kegiatan ekonomi produktif, dimana saat pra konversi yaitu sebagai petani tanaman pangan, buruh tani peternak, nelayan, pedagang, buruh bangunan dan tukang ojek sedangkan pasca konversi bertambah yakni sebagai pekasih dengan kontribusi pendapatan sebesar 1,72\%, sopir truk dengan kontribusi pendapatan sebesar 0,65 \% dan buruh bangunan dengan kontribusi pendapatan sebesar $0,45 \%$ dari total pendapatan rumahtangga petani.

b. Konversi lahan mengakibatkan penurunan kontribusi pendapatan usahatani sebesar Rp 4.427.128/tahun atau sebesar 18,51 \% dari total pendapatan rumahtangga petani.

c. Dampak konversi lahan terhadap pola konsumsi pangan rumahtangga petani di Kota Mataram yakni adanya perubahan pola konsumsi pangan dimana konsumsi 
karbohidrat meningkat sebesar 1,60\%, konsumsi lauk hewani menurun sebesar $0,19 \mathrm{~kg} / \mathrm{kapita} / \mathrm{bulan}$ atau mennurun $1,11 \%$ menyebabkan peningkatan konsumsi lauk nabati sebesar $0,67 \mathrm{~kg} / \mathrm{kapita} /$ bulan atau meningkat $3,36 \%$ dari total konsumsi pangan.

d. Konversi lahan mengakibatkan penurunan jumlah konsumsi pangan sebesar $1,54 \%$ atau $0,30 \mathrm{~kg} / \mathrm{kapita} / \mathrm{bulan}$ senilai Rp 13.648,81/kapita/bulan.

e. Dampak konversi lahan terhadap pola konsumsi non pangan rumahtangga petani adalah penurunan konsumsi pada pakaian sebesar 2,68 \%, rekreasi sebesar 3,68 \% dan tabungan sebesar $12,04 \%$ dari total konumsi non pangan.

f. Masalah tertinggi yang dirasakan petani setelah konversi lahan adalah harga bahan pangan yang tinggi, kemudian nilai tukar petani rendah, serangan hama/penyakit dan kesuburan tanah yang kurang baik.

\section{Saran}

a. Untuk mengatasai berkurangnya luas pengusahaan lahan pertanian yang langsung berdampak menurunkan pendapatan maka diharapkan kepada petani di Kota Mataram mengembangkan sistem pertanian yang hemat lahan seperti sistem pertanian modern seperti hydroponik dan aeroponik.

b. Kepada pihak pemerintah dan swasta terkait diharapkan memberi penyuluhan yang intensif kepada petani Kota Mataram tentang intensifikasi pertanian agar produktivitas meningkat serta penyuluhan berbagai komoditi non tanaman panganyang bernilai ekonomi tinggi dan dibutuhkan masyarakat perkotaan, memberi penyuluhan untuk pengembangan kegiatan ekonomi produktif lain agar terserap tenaga menganggur akibat konversi lahan di Kota Mataram..

c. Kepada pemerintah diharapkan mengendalikan konversi lahan dengan mengembangkan pajak progresif pada lahan non pertanian untuk mengurangi permintaan lahan yang berlebihan dan penerapan sistem ekstensifikasi pertanian melalui percetakan sawah baru agar bisa menggantikan lahan yang sudah terkonversi.

\section{DAFTAR PUSTAKA}

Badan Pusat Statistik. 2017. Kota Mataram dalam Angka Tahun 2017. BPS KotaMataram. Mataram.

Permatasari, AD. 2014. "Dampak Pembangunan Bandara Internasional Lombok (BIL) terhadap Pola Produksi dan Pola Konsumsi di Desa Tanaq Awu Kecamatan Pujut Kabupaten Lombok Tengah". [Skripsi]. Pertanian, Agribisnis. Universitas Mataram.

Tajidan. "Kajian Teoritis dan Empiris Luas Lahan Pertanian Optimum yang Mendukung Ketahanan Pangan Wilayah Perkotaan di Kota Mataram”. https://www.academia.edu/24382979/Luas_Lahan_Pertanian.Diakses pada tanggal 28 Januari 2017. 